\title{
Impact of Occupational Stress, Interpersonal Trust, and Organizational Commitment on Valence, OCB and Job Satisfaction: A Variance-Based SEM Analysis
}

\author{
Muhammad Shahnawaz Adil * \\ Muhammad Owais ${ }^{\dagger}$ \\ Ambreen Qamar $\ddagger$
}

\begin{abstract}
This study analyzes the impact of these three cognitive forces (occupational stress, interpersonal trust and organizational commitment) on valence, Organizational citizenship behavior (OCB) and job satisfaction in the healthcare sector of Karachi (Pakistan). A sample of 375 responses is drawn from seven healthcare institutions of Karachi on a self-administered questionnaire. Using PLS-SEM, hypotheses and predictive relevance are tested with bootstrapping method and cross-validated redundancy analysis respectively. The results show that all three cognitive forces have significant impact on valence with the minor exception of affective commitment and strain. Moreover, valence has significant impact on both OCB has also shown a significant effect on job satisfaction. OCB has also shown a significant effect on job satisfaction. The findings of this study substantially contribute in the under-researched domain of OCB and job satisfaction in the context of the healthcare sector of Pakistan. Managerial implications and directions for future research are also discussed.
\end{abstract}

Keywords: Occupational stress, trust, organizational commitment, valence, organizational citizenship behavior, job satisfaction, healthcare, Pakistan.

\section{Introduction}

In organizational studies, valence refers to "... all possible affective orientations toward outcomes, and it is interpreted as the importance, attractiveness, desirability, or anticipated satisfaction with outcomes" (Vroom, 1964). It is an affective alignment on the way to a specific end result. The cognitive forces consist of the drivers which predict the valence of job satisfaction (Mitchell, 1974). These forces include occupational stress, interpersonal trust at work, and organizational commitment. These three antecedences not

*Assistant Professor at Department of Management Sciences, IQRA University, Karachi, Pakistan.

E-mail: adil.s@iuk.edu.pk

${ }^{\dagger}$ Deputy Director at Institute of Basic Medical Sciences, Dow University of Health Sciences, Karachi, Pakistan.

E-mail: muhammad.owais@duhs.edu.pk

${ }^{\ddagger}$ Department of Physiology, Dow International Medical College, Dow University of Health Sciences, Karachi,

Pakistan. E-mail: a_smcian@yahoo.com.

Acknowledgement: The authors would like to pay their sincere gratitude to Prof. Dr. Masood Qureshi, Director Institute of Basic Medical Sciences, DOW University of Health Sciences and Prof. Dr. Ghulam Sarwar, Principal, Sindh Medical College for their guidance and motivation throughout the study. The authors also thank Dr. Rabia Arshad and Dr. Khushbakht Nawaz Khan for their assistance in data collection from different healthcare institutions of Karachi. In addition, the authors also wish to thank Dr. James Gaskin (Assistant Professor, Department of Information Systems, Brigham Young University, Utah, United States) for providing his very useful video tutorials of PLS-SEM on his StatWiki Website.

The authors would like to thank both reviewers for their valuable suggestions to improve the manuscript. 
only affect the valence of job satisfaction but also influence the organizational citizenship behavior which could further lead to affect the overall job satisfaction. Organ, Podsakoff, and MacKenzie (2005) defined organizational citizenship behavior (henceforth, 'OCB') as an "individual behavior that is discretionary, not directly or explicitly recognized by the formal reward system, and in the aggregate promotes the efficient and effective functioning of the organization". These activities are directed more in creating effective relationships and then task completion. To exhibit OCB, it is required for employees to participate voluntarily in workplace bearing in mind that these efforts may not be rewarded. When many members of a work unit or organization perform OCB consistently over a period of time, not only the interpersonal relationships but also organizational performance is improved (N. P. Podsakoff, Whiting, Podsakoff, \& Blume, 2009).

The specific kinds of behaviors considered to manifestations of OCB have been evolving over time (Bateman \& Organ, 1983). Examples include taking the initiative to orient new colleagues, volunteering to attend events that help them improve the image of the organization (Organ et al., 2005). In the most commonly-used framework, OCB is categorized into five-dimensions: altruism, conscientiousness, sportsmanship, courtesy, and civic virtue (LePine, Erez, \& Johnson, 2002; Organ et al., 2005). These behaviors are often distinguished in the literature by their intended purpose, which can be other individuals (OCB-I) such as Trust in Supervisors, co-workers, or customers, or the organization itself (OCB-O) (Morrison, 1996; Williams \& Anderson, 1991).

Occupational stress is the consequences of the encounter of employee with the undesired work's conditions (Rashid \& Talib, 2015). The literature clearly shows that occupational stress affects physical and mental health of employees. Specifically, occupational stress may lead to coronary heart diseases (Fitzgerald, Brown, Sonnega, \& Ewart, 2005), emotional exhaustion and depression (Beehr, King, \& King, 1990), and musculoskeletal disorder, diabetes, and cancer (Kristensen, 1996). Although, views may vary, the working conditions and even the characteristics of the worker serve as the primary reasons of developing occupational stress. These conflicting perspectives are important because they drive different approaches to foil work stress in the working conditions. Therefore, an individual with occupational stress may develop psychological problems such as anxiety, depression, and nervousness (Cooper \& Marshall, 2013).

The organizational commitment concept has fascinated much attention in trying to identify the severity and stability of the dedication of employees in their profession (Eisenberg, Fasolo, \& Davis-LaMastro, 1990). Despite the growing interest in organizational commitment, it seems to have much ambiguity and differences of opinion about what commitment is? Where it is headed? How it is evolved? How does it affect the employee's behavior? (Meyer \& Herscovitch, 2001). Job satisfaction among employees is an important characteristic in predicting high performance (Oshagbemi, 2003). Job satisfaction is related to firm performance and productivity, regulatory and other issues, including labor turnover. However, disgruntled employees are often prone to excessive absenteeism and turnover (Chen, Yang, Shiau, \& Wang, 2006) which have attracted the attention of managers (Nizam \& Adil, 2014). Job satisfaction is an important factor to improve the efficiency and high-performance work systems. 


\section{Healthcare in Pakistan}

In Pakistan, almost 75 percent of the total population lives in the rural areas of the country where the healthcare facilities are highly questioned. However, healthcare services are provided by both public and private sectors mainly in Karachi. Nursing is considered as one of the major components of the healthcare system in the country. There are a number of nursing schools operating in the city where they encourage nurses to gain certifications for better employment prospects. During 1980s and 1990s, the Canadian International Development Agency has made a substantial amount of funding in nursing education in the country. Pakistan Nursing Council (PNC) is a regulatory authority established in 1948 to safeguard the interests of healthcare professionals, formulate and standardize the working standards for nursing schools, approves relevant academic and professional programs, etc.

According to the World Health Organization (2014) report, there is a shortage of 7.2 million skilled health care workers globally, which is expected to rise up to 12.9 million by 2035 . This situation is more or less same as Pakistan. Because of high rates of unemployment in Karachi, health care professional tends to suffer from a high work anxiety, fatigue and increasing workload. Even healthcare institutions face difficulty in recruiting such healthcare professional which could serve in the organization for a longer period of time. Employees are given various trainings and workshops for their professional development, however, due to high inflation some of the healthcare employers are not in a position to offer competitive financial benefits to their employees. Since, the healthcare professionals face difficulty and notable hindrances in moving from one organization to another, they tend to continue with their present job as compulsion (called continuance commitment). Notwithstanding, it is often observed that the healthcare professionals suffer from occupational stress, which hinders them to exhibit OCB. Moreover, the interpersonal trust among co-workers and supervisors and organizational commitment are significantly related with a valence of job satisfaction.

The purpose of this quantitative study is to investigate the impact of three cognitive forces (namely, occupational stress, interpersonal trust and organizational commitment) on valence, organizational citizenship behavior and job satisfaction of the healthcare professionals in Karachi, Pakistan however, investigating the mediating role of latent constructs is beyond the scope of this non-parametric multivariate structural analysis. The purpose of this study is to investigate the impact of three cognitive forces (namely, occupational stress, interpersonal trust and organizational commitment) on valence, organizational citizenship behavior and job satisfaction of the healthcare professionals in Karachi, Pakistan. The higher rate of turnover intention and job dissatisfaction among healthcare professionals in Pakistan makes this study very important to be conducted in Pakistan. Besides, this study contributes to the existing body of knowledge in a manner that it combines the aforementioned three cognitive forces and investigates its holistic multivariate impact on OCB and ultimately on the job satisfaction. Notably, a very little is known about these variables in order to determine the job satisfaction of healthcare professionals in the Pakistani social context. 


\section{Theoretical Background and Hypotheses}

The subject of occupational stress has been extensively studied in the past, however, it has gained an increased amount of interest among healthcare professionals because of the involvement of technology in this profession. At one side, healthcare professionals tend to adapt state-of-the-art technologies to perform better, faster and accurate in their respective domain. But exactly at the same time, they are exposed to heavy workloads which often lead to occupational stress (Nowrouzi et al., 2015). This phenomenon is reflected in the form of deterioration in their physiological, psychological and emotional states. Therefore, according to Rashid and Talib (2015), a great emphasis has been given to analyze those measures which could mitigate the repercussion of occupational stress or even provide the subject with a situation and knowledge where occupational stress could not be observed in future. These adjustive reactions (or coping behaviors) are classified into three broad categories in the literature: a) problem-focused coping behavior in which a closed attention is given to change the environment so that the chances of events could be alleviated (Ben-Zur, Yagil, \& Oz, 2005); b) emotion-focused coping behavior in which the affects or emotions associated with the stressor are either reduced or eliminated (Carver, Scheier, \& Weintraub, 1989); and c) avoidant coping behavior in which the person simply avoids the stressor as much as possible (Roth \& Cohen, 1986). This occupational stress not only affects the employee, but also affects the healthcare institution (Abdel-Halim, 1982).

Trust is an indispensable component to the success of multi-party efforts and a symbol of effective relationships (Cyr, 1999). In organizational sciences, the experts tend to agree on this problem (R. M. Kramer \& Tyler, 1996), though a limited understanding is there of precisely explain the role of interpersonal trust in the supervisor and subordinate relationship. Precisely, the operational definitions of trust and belief include whether the partner is reliable (McAllister, 1995); takes care of your own interests (Cook \& Wall, 1980); and/or dispose of integrity (Robinson, 1996). In addition, the conceptual advocates argue that trust is separate from other variables for group cohesion and group fascination of its members; friendship and close ties that exist among the people (Jehn \& Shah, 1997); and knowledge, and particular information of the other (Goodman \& Leyden, 1991).

Organizational commitment is an important dimension of behavior that can be used to assess the strength of attachment of staff. In connection with the involvement of the organization, the work-related factors are very important: staff turnover, absenteeism, and performance (Romzek, 1990). The perception of organizational commitment regularly improves emotional attachment to the organization in the form of sharing the values of the organization, their desire to stay in the organization, and their willingness to commit themselves to the benefits of the organization. It is committed due to which employees show their vigorous affiliation with the organization in order to give their best for the welfare of the institution (Mowday, Steers, \& Porter, 1979). It is widely understood that those who are deeply involved in the organizations and demonstrate their organizational commitment tend to stay longer in the organization (Meyer, Allen, \& Gellatly, 1990). In the past, affective (want to), continuance (have to), and normative (ought to) are the three classifications of organizational commitment (Meyer \& Allen, 1991). Hence, the following hypothesis is suggested: 
$H_{1}$ : Cognitive forces (i.e. occupational stress, interpersonal trust between the supervisor and colleagues, and organizational commitment) have significant impact on valence.

Job satisfaction is a means through which organization can acquire certain information from its employees e.g. Their viewpoints, feelings and personal preferences and expectations as well as their interest in their jobs (Lambert, Hogan, \& Griffin, 2007). This information enables managers to understand whether their employees are satisfied with their jobs and financial benefits and these are compatible with their efforts, in particular. There are two very important reasons for being concerned with job satisfaction: a) Job satisfaction can lead to happier and more attractive life; b) It contributes in shaping the person's family and job attitudes.

Good professional relationship with physicians, greater nurses control over working practices and decisions regarding patient care and useful and positive teamwork perceptions are the key characteristics of professional nursing practice environment (Lake, 2007, 2002). These characteristics are essential in harmonizing a culture which reinforces inter-professional collaborations (Orchard, Curran, \& Kabene, 2005). Moreover, eight hallmarks have been introduced by the American Association of Colleges of Nursing (2002). The term of "Magnet Hospitals" has been used in both literature and practice because of the professional nursing practice environment which provides strong and visible nursing practices through authentic leadership and appropriate level of structural empowerment given to nurses (M. Kramer \& Hafner, 1989). This is generally referred to as 'good place to work' where one can observe higher nurses' job satisfaction as well as career growth within the healthcare institution (Lake, 2002) which is reflected in the form of patient outcomes e.g. higher perceived quality of care and lower mortality and morbidity (Djukic, Kovner, Brewer, Fatehi, \& Cline, 2013).

$\mathrm{H}_{2}$ : Valence has significant impact on organizational citizenship behavior when controlling for the level of responsibility and work experience of the healthcare professionals in their present organization.

$H_{3}$ : Valence has significant impact on job satisfaction among the healthcare professionals in Karachi when controlling for their gender, marital status, highest qualification, and total work experience.

OCB refers to an "individual conduct that is unrestrictedly not directly or clearly known by the formal reward system, and in the aggregate promotes the efficient and effective functioning of an organization" (Organ et al., 2005). Interestingly, since male employees are more career-oriented than females, they are more likely to be interested in getting a favorable appraisal and reviews ( $\mathrm{Ng}$, Lam, \& Feldman, 2016). Due to the significance of OCB for organizational functioning, background and precursors of OCBs have been examined in numerous studies. It is emphasized that employees who diligently displayed greater levels of job satisfaction exhibited higher OCB (Lapierre \& Hackett, 2007). Some other precursors of OCB are confronting, compromising, and smoothing strategies. 
Chiaburu, Oh, Berry, Li, and Gardner (2011) established the stronger relationship of openness and agreeableness with OCB than the role performance after examining Big-five personality trait and OCB.

$\mathrm{H}_{4}$ : Organizational citizenship behavior has significant impact on job satisfaction when controlling for their gender, marital status, highest qualification, and total work experience.

\section{Method}

\section{Samples and Procedures}

The research philosophy of this study encompasses the 'Realism' belief of Ontology which in turn, dictates the 'Etic' approach of Epistemology for this study (Bryman, 2012; Sekaran \& Bougie, 2016). In particular, realists believe that one truth exists; truth does not change; and the truth can be discovered using objective measurements. Moreover, once we find out what the truth is, we can generalize it to other situations. In this study, the authors posited different hypotheses to maintain that there is one truth which could establish a relationship between an IV and a DV; in other words, the results could possibly conclude whether there is (or isn't) a direct impact. It implies that there will be a non-recursive relationship from an IV towards a DV which is due to its unidirectional nature of causal relationship, i.e. the truth about the reality between two latent variables does not change. Besides, the use of Likert scale items (as an objective measurement to quantify each study variables) also endorses that the truth can be discovered using objective measurements. Finally, since there will be one truth exists regarding the relationship between each of the two study variables, the research findings may be generalized on a larger population of similar social and study contexts.

Furthermore, due to realism Ontological belief, the study employed an etic approach to know the reality (called Epistemology). Using the 'etic' approach, the authors distributed the survey questionnaires without becoming an integral part of the respondent's work system and most importantly, without disturbing the reality which were being studied. Based on these philosophical beliefs (realism with etic approach), the authors believe that there is one truth exist which can be assessed by using objective measurements.

The research design of this empirical study followed a deductive reasoning in which the authors used a quantitative research approach to perform an explanatory study to test research hypotheses. Notably, this was a causal and cross-sectional study which was conducted in a non-contrived field study setting. The unit of analysis is the 'individual' working in the public and private healthcare institutions of Karachi, Pakistan.

The target population of this study included all individuals (both male and female employees) ages 25 and above having at least graduate-level education and working on a full-time basis in a healthcare institution (either public, private, semi-public or missionary hospitals) of Karachi, Pakistan in 2016-17. However, the study (or accessible population) comprised of all of the individuals who were employed in only seven healthcare institutions (namely, Dow University of Health Sciences, Liaquat National Hospital, Aga Khan 
University Hospital, Ziauddin Medical University, Baqai Medical University, Liaquat College of Medicine and Dentistry, Jinnah Sindh Medical University) having aforementioned demographical idiosyncrasies.

Despite a number of attempts to gain an officially-approved list of individuals from these seven institutions to employing probability sampling technique, the authors remained unsuccessful to obtain even a best approximation of sampling frame. Consequently, a non-probability convenience sampling technique was used to draw a sample of 375 responses on a self-completion survey questionnaire from these seven institutions.

During initial data screening phase, a total of 83 univariate and multivariate outliers were detected and removed from the dataset by using standardized ( $Z$ ) score and Mahalanobis Distance value at $\mathrm{p}<0.001$ ) respectively (Tabachnick \& Fidell, 2013). It resulted in a sample of 292 useable responses for data analysis. The response rate was 78 percent.

In addition, Harman's single factor test (Schriesheim, 1979) was used in SPSS to assess the potential presence of common method variance (CMV) bias (P. M. Podsakoff, MacKenzie, Lee, \& Podsakoff, 2003). All 96 observed items (or indicators) used in the survey questionnaire cumulatively accounted for only $12.8 \%$ of the total variance by an un-rotated factor which is less than $50 \%$ of the threshold value (P. M. Podsakoff \& Organ, 1986; Scott \& Bruce, 1994). It warrants that the data is free from the CMV bias e.g. (Andersson \& Bateman, 1997; Aulakh \& Gencturk, 2000) and we may proceed further with the data analysis (Adil, Awais, Khan, \& Qureshi, 2019).

The useable sample comprises of 148 responses from the public sector (50.7 percent), 136 from the private sector (46.6 percent), and 8 responses from the semi-government healthcare institutions. Overall, 127 respondents were associated with teaching medical education (43.5 percent), 57 respondents were from hospital administrative staff (19.5 percent), and the rests of the 108 responses held both the teaching and administrative positions (37 percent). Table 1 shows some other demographic items in the sample drawn.

\section{Measures}

The study used three cognitive forces as exogenous latent variables, namely, occupational stress, interpersonal trust, and organizational commitment, whereas valence, organizational citizenship behavior, and job satisfaction are the endogenous latent variables. The control variables include level of responsibility, work experience with the present employer, gender, marital status, highest qualification, and total work experience of the respondents. The data of 96 items were collected in a five-point Likert scale administered to them ranging from 1 (strongly disagree) to 5 (strongly agree). The first stage Cronbach alpha of these 96 items was 0.88 . The measurement of these constructs is described below: 
Table 1

Composition of Data $(\mathrm{N}=292)$

\begin{tabular}{|c|c|c|c|}
\hline Variables & & Frequency & Percent \\
\hline \multirow[t]{2}{*}{ Gender } & Male & 106 & 36.3 \\
\hline & Female & 186 & 63.7 \\
\hline \multirow{5}{*}{$\begin{array}{l}\text { Age } \\
\text { (in years) }\end{array}$} & $25-35$ & 193 & 66.1 \\
\hline & $36-45$ & 65 & 22.3 \\
\hline & $46-55$ & 22 & 7.5 \\
\hline & $56-65$ & 9 & 3.1 \\
\hline & Above 65 & 3 & 1.0 \\
\hline \multirow{4}{*}{ Marital Status } & Single & 93 & 31.8 \\
\hline & Married & 87 & 29.8 \\
\hline & Married with children & 108 & 37.0 \\
\hline & Separated/Divorced/ Widow & 4 & 1.4 \\
\hline \multirow{5}{*}{ Level of Responsibility } & Member of the Board & 9 & 3.1 \\
\hline & Senior Management & 13 & 4.5 \\
\hline & Middle Management & 92 & 31.5 \\
\hline & Operational Management & 145 & 49.7 \\
\hline & Supervisor & 33 & 11.3 \\
\hline \multirow{6}{*}{$\begin{array}{l}\text { Work Experience in } \\
\text { Present Organization }\end{array}$} & Less than 2 Years & 110 & 37.7 \\
\hline & Between 03 and 05 Years & 99 & 33.9 \\
\hline & Between 06 and 10 Years & 51 & 17.5 \\
\hline & Between 11 and 15 Years & 18 & 6.2 \\
\hline & Between 16 and 25 Years & 13 & 4.5 \\
\hline & More than 26 Years & 1 & .3 \\
\hline \multirow{6}{*}{ Total Work Experience } & Less than 2 Years & 61 & 20.9 \\
\hline & Between 03 and 05 Years & 76 & 26.0 \\
\hline & Between 06 and 10 Years & 78 & 26.7 \\
\hline & Between 11 and 15 Years & 36 & 12.3 \\
\hline & Between 16 and 25 Years & 29 & 9.9 \\
\hline & More than 26 Years & 12 & 4.1 \\
\hline \multirow{3}{*}{ Highest Qualification } & Graduate & 167 & 57.2 \\
\hline & Postgraduate & 116 & 39.7 \\
\hline & $\mathrm{PhD}$ & 9 & 3.1 \\
\hline
\end{tabular}

Occupational stress was measured by an 18-item scale adapted from Schaufeli, Leiter, and Kalimo (1995) with three sub-scales: occupational role, personal strain and personal resource. The first stage Cronbach alpha was 0.68 . Interpersonal trust was measured by a 12-item scale developed by Cook and Wall (1980). The first stage Cronbach alpha of this scale was 0.70. A total of 24 items in the form of three sub-scales were used to measure organizational commitment: affective, continuance, and normative commitment (Allen \& Meyer, 1990). There were 9 reverse coded items. The first stage Cronbach alpha of this scale was 0.63 . Valence (of job satisfaction) was measured by using 13 items adapted from Teas (1981). The first stage alpha of this scale was 0.88. Organizational Citizenship Behavior was measured by 24 items adapted from Moorman (1993). The first stage alpha of this scale was 0.82. Job satisfaction was measured by 5 items adapted from Lee, Mitchell, Holtom, McDaneil, and Hill (1999). The first stage alpha of this scale was 0.64.

\section{Data Analysis}

Data were analyzed by using SmartPLS version 3 software developed by Ringle, Wende, and Becker (2015) with Partial Least Squares Structural Equation Modeling (henceforth, 
'PLS-SEM').

\section{Reasons of Applying PLS-SEM in this Study}

Because of the following five prime reasons, PLS-SEM is preferred as the most suitable SEM technique for this study instead of covariance-based SEM (Hair Jr, Hult, Ringle, \& Sarstedt, 2016; Sarkkinen \& K'assi, 2015):

1. Both the measurement and structural models are 'formative' in nature, the study required the weights of the indicator variables which affect its latent variable. The formative model is the one where the direction of the arrows is from the measured (Likert-scale) items towards the latent variable (Hair Jr et al., 2016).

2. 'Prediction' was the main purpose of the inner model which requires each of the endogenous variables to show maximum 'variance' (not covariance) to be explained by all of its exogenous variables.

3. Early stages of developing perhaps a new theory which involves cognitive forces, valence, OCB and job satisfaction in the healthcare sector of Pakistan.

4. The model was complex (i.e. 96 Likert-scale items; 6 latent constructs with 14 subscales) with smaller sample size $(\mathrm{n}=292)$.

5. The fifth reason of using a non-parametric SEM technique is that the data were not from multivariate normal distribution. For this, the study used Royston's H test in StatGraphics ${ }^{\circledR}$ Centurion software (version 18.1.06) to assess multivariate normality. This tests actually combines Shapiro-Wilk tests for all endogenous latent variables. In this study valence, organizational citizenship behavior and job satisfaction are the three endogenous latent variables. Royston's H test value was 89.447 $(\mathrm{p}<0.001)$ indicating that the distribution is not multivariate normal (see Table 2$)$.

Table 2

Royston's H test for assessing Multivariate Normality

\begin{tabular}{lcc}
\hline Normality Tests & Statistics & P-Value \\
\hline Shapiro-Wilk W - Valence & 0.968 & 0.000 \\
Shapiro-Wilk W - OCB & 0.984 & 0.002 \\
Shapiro-Wilk W - JS & 0.879 & 0.000 \\
Royston's H & 89.447 & 0.000 \\
\hline Not Nu
\end{tabular}

Note: Number of observations $=292$

In addition, Figure 1 depicts a second way to test whether our data has come from a multivariate normal distribution using a chi-square distribution plot. In a chi-square plot we plot the squared generalized distances between our data points; one plot in an $\mathrm{m}$-dimensional space and the centroid of the data. If in fact, the data come from a ' $\mathrm{m}$ ' variable multivariate normal distribution then these squared distances should come from a chi-square distribution within ' $\mathrm{m}$ ' degrees of freedom. Figure 1 clearly illustrates that majority of the data points do not fall within the $95 \%$ confidence KolmogorovSmirnov 
(K-S) limit $(0.125 ; \mathrm{p}<0.001)$. In short, based on both Royston's $\mathrm{H}$ test and the chi-square distribution plot, it was concluded that the data used in this study did not meet the assumption of multivariate normality. Therefore, non-parametric SEM with non-parametric bootstrapping method were used to test research hypotheses.

\section{Figure 1}

Multivariate Normality using Chi-Square Distribution

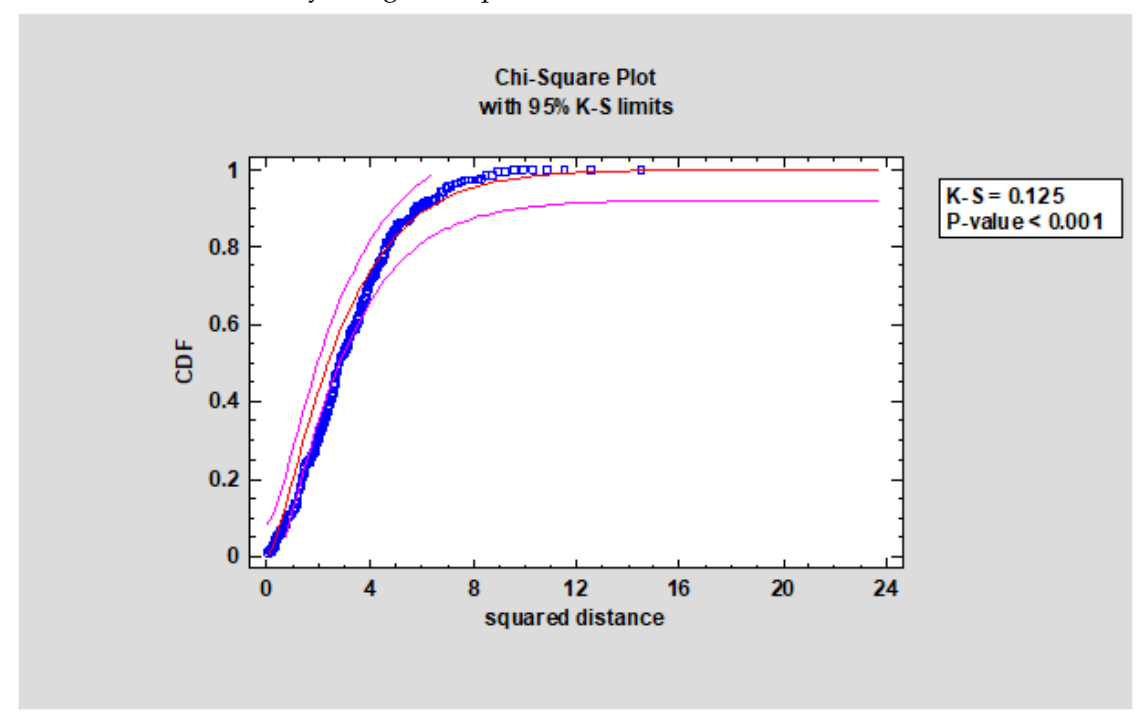

\section{Statistical Power Analysis}

Since the purpose was to predict the three endogenous variables (valence, OCB and job satisfaction) based on maximum shared variance therefore, it was very important to reduce Type-II error. For this a higher statistical power was required to achieve. For the said purpose, G*Power version 3.1 software (Faul, Erdfelder, Buchner, \& Lang, 2009) was used. A post-hoc power analysis was computed given the significance level significance level $(\alpha)=0.05$, sample size $=292$, and population high effect size $=0.35$. It results in a very high statistical power, i.e. 1.0. In other words, the occurrence of committing Type-II error has been eliminated from this study. For further description of the rules of thumb for selecting covariance-based SEM or PLS-SEM, refer Hair, Ringle, and Sarstedt (2011). In addition, (Hair, Sarstedt, Ringle, \& Mena, 2012) provides useful guidelines for applying PLS-SEM.

\section{Formative Measurement Model}

A formative measurement model was constructed because it was hypothesized that three cognitive forces will impact the valence of job satisfaction. Therefore, the changes in the indicator variables are expected to determine changes in the value of its respective latent 
construct (Hair et al., 2011). For example, eight indicator variables (i.e. Likert-scale items) of 'affective' sub-scale of organizational commitment will determine the magnitude of 'Valence'. Similarly, interpersonal trust in supervisor and co-workers will influence the 'Valence' too. It is important to note that composite reliability (CR), convergent validity through average variance extracted (AVE), and discriminant validity through interconstructs correlations using Fornell-Larcker criterion is reported in 'Reflective' measurement model (Edwards, 2011; Hair et al., 2012). On the contrary, (Hair et al., 2012) suggested the following estimations to report for evaluating the formative measurement model. Please note that measurement and structural models are often called outer and inner models respectively (Hair et al., 2012) as shown in Table 3:

a) Indicator weights instead of factor loadings;

b) t-statistic, p-value or standard errors; and

c) Variance inflation factor (VIF)

Interestingly, Hair et al. (2012) mentioned that it is necessary to report the statistical significance of each outer weight. In fact, this important issue has been largely condoned by previous researchers. As shown in Table 3, there are 16 weights which have been found statistically significant at 95 percent confidence level (i.e. t-statistic $\geq|1.96|$ and $\mathrm{p}<0.05$ ) to determine the effect on their respective latent variable (henceforth, LV). These 16 significant weights range from 0.27 to 0.93 . Except the LV of 'Strain', all LVs have one or more significant outer weights.

Since, the 'weights' of the formative model are smaller than the 'loadings' of a reflective model, therefore, one may be misled for interpretation by merely looking at the outer weights (Diamantopoulos \& Winklhofer, 2001). In essence, there is likelihood that the weights of the indicators may be unstable (Cenfetelli \& Bassellier, 2009). Therefore, variance inflation factor (VIF) should also be reported to assess multicollinearity between indicators (Hair et al., 2012). Table 3 shows that the VIF of all of the indicators is less than 3 . Hence, there is no problem of multicollinearity in the formative measurement model (Hair et al., 2011).

\section{Hypotheses Testing Using Bootstrapping}

There are four major hypotheses in this study. Hypothesis 1 analyzes the separate impact of three cognitive forces on valence. Hypothesis 2 and 3 ascertain the impact of valence on OCB and job satisfaction respectively whereas hypothesis 4 investigates the impact of OCB on job satisfaction. Using PLS-SEM algorithm in the SmartPLS 3.0 software, a structural (inner) model was developed to test these four hypotheses. In fact, in PLS-SEM bootstrap samples are generated to estimate the statistical significance of parameter estimates (Henseler, Ringle, \& Sinkovics, 2009). Therefore, in this study, a 5,000 non-parametric bootstrap samples were generated by Bias-Corrected and Accelerated (BCA) Bootstrap method of the confidence interval (Davison \& Hinkley, 1997; Efron \& Tibshirani, 1994). Testing with confidence interval tends to provide more information about the parameter 


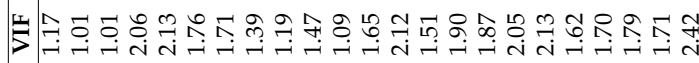

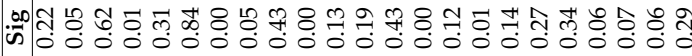

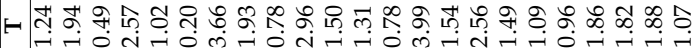

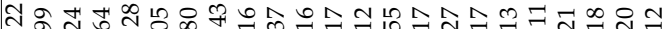

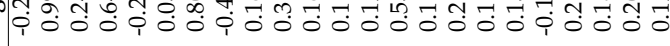

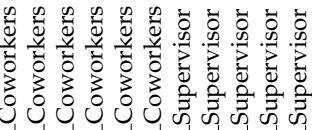

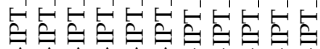

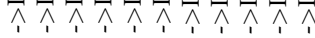

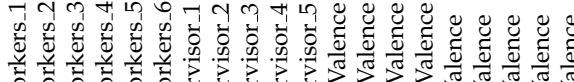

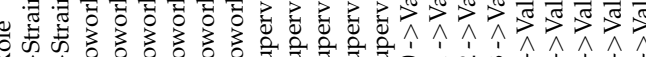

此

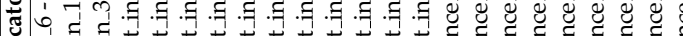

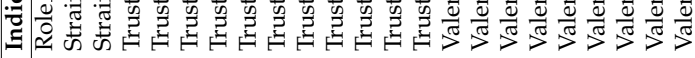

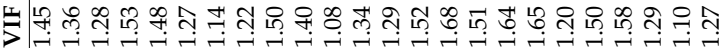

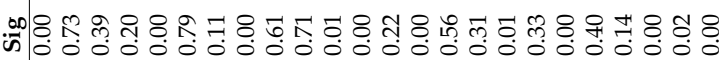

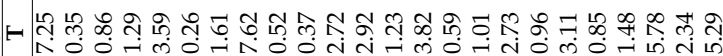

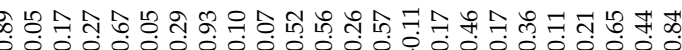


estimates (Henseler et al., 2009) because 'if the hypothesis is not rejected, the power of the procedure can be gauged by the width of the interval' (Shaffer, 1995).

Likewise for the outer model, Hair et al. (2012) also recommended the following estimations to report for evaluating the formative inner mode as shown in Table 4:
a) $R^{2}$
b) Effect Size $\left(f^{2}\right)$
c) Parameter estimates using bootstrapping
d) Confidence intervals
e) Predictive relevance $Q^{2}$ and $q^{2}$

\section{Table 4}

Path Analysis Using PLS - SEM (Bootstrapping)

(when controlling for level of responsibility, work experience in the present organization, gender, marital status, highest qualification, and overall work experience)

\begin{tabular}{|c|c|c|c|c|c|c|}
\hline \multirow[t]{2}{*}{ Regression Path } & \multirow{2}{*}{ Estimates } & \multirow{2}{*}{ T Statistics } & \multirow{2}{*}{ Sig } & \multirow[t]{2}{*}{ Effect Size } & \multicolumn{2}{|c|}{ Confidence Interval } \\
\hline & & & & & $2.5 \%$ & $97.5 \%$ \\
\hline Resources -> Valence & 0.26 & 4.35 & $0.000^{* * *}$ & 0.10 & 0.13 & 0.36 \\
\hline Role ->Valence & 0.15 & 2.89 & $0.004^{* *}$ & 0.04 & 0.03 & 0.22 \\
\hline IPT_Coworkers ->Valence & 0.11 & 1.96 & $0.050^{*}$ & 0.03 & 0.04 & 0.26 \\
\hline IPT_Supervisor ->Valence & 0.30 & 5.18 & $0.000^{* * *}$ & 0.11 & 0.16 & 0.39 \\
\hline CC ->Valence & 0.19 & 3.19 & $0.001^{* *}$ & 0.07 & 0.09 & 0.32 \\
\hline Valence ->OCB & 0.46 & 7.66 & $0.000^{* * *}$ & 0.32 & 0.41 & 0.63 \\
\hline Valence ->JS & 0.30 & 3.93 & $0.000^{* * *}$ & 0.10 & 0.17 & 0.46 \\
\hline OCB ->JS & 0.20 & 2.23 & $0.026^{*}$ & 0.05 & 0.06 & 0.40 \\
\hline NC -> Valence & 0.11 & 1.84 & 0.065 & 0.03 & 0.01 & 0.23 \\
\hline AC ->Valence & 0.04 & 0.65 & 0.514 & 0.01 & -0.05 & 0.20 \\
\hline Strain ->Valence & -0.08 & 1.22 & 0.221 & 0.01 & -0.07 & 0.21 \\
\hline
\end{tabular}

With two exceptions (i.e. affective commitment and strain) rests of the hypotheses are supported. More specifically, the three cognitive forces have shown a statistically significant impact on valence thus hypothesis 1 is supported. Moreover, valence has shown statistically significant impact on both OCB $(0.46, \mathrm{p}=.000)$ and job satisfaction $(0.30, \mathrm{p}=.000)$ thus, hypothesis 2 and 3 are also supported. In addition, OCB has also shown significant impact on job satisfaction $(0.20, p=.026)$ thus, hypothesis 4 is also supported.

Albeit, the t-statistic of normative commitment is slightly less than $|1.96|$ to gain statistical significance at 95\% CI $(p<0.05)$ however, its confidence interval does not include zero enabling this sub-scale of organizational commitment significant at 90 percent confidence level $(p<0.10)$. However, the confidence interval of both affective commitment and strain include zero, thus only these two subscales may not be considered significant in predicting valence. The eight formative measures of valence predict over 51 percent of the total variance; valence itself predicts 24 percent of the total variance; and both valence and OCB predict a total of 25 percent of the total variance in explaining job satisfaction. These estimates in the presence of six control variables are illustrated graphically in Figure 2. 
Figure 2

Structural Relationship: Cognitive Forces, Valence, Organizational Citizenship Behavior, and Job Satisfaction

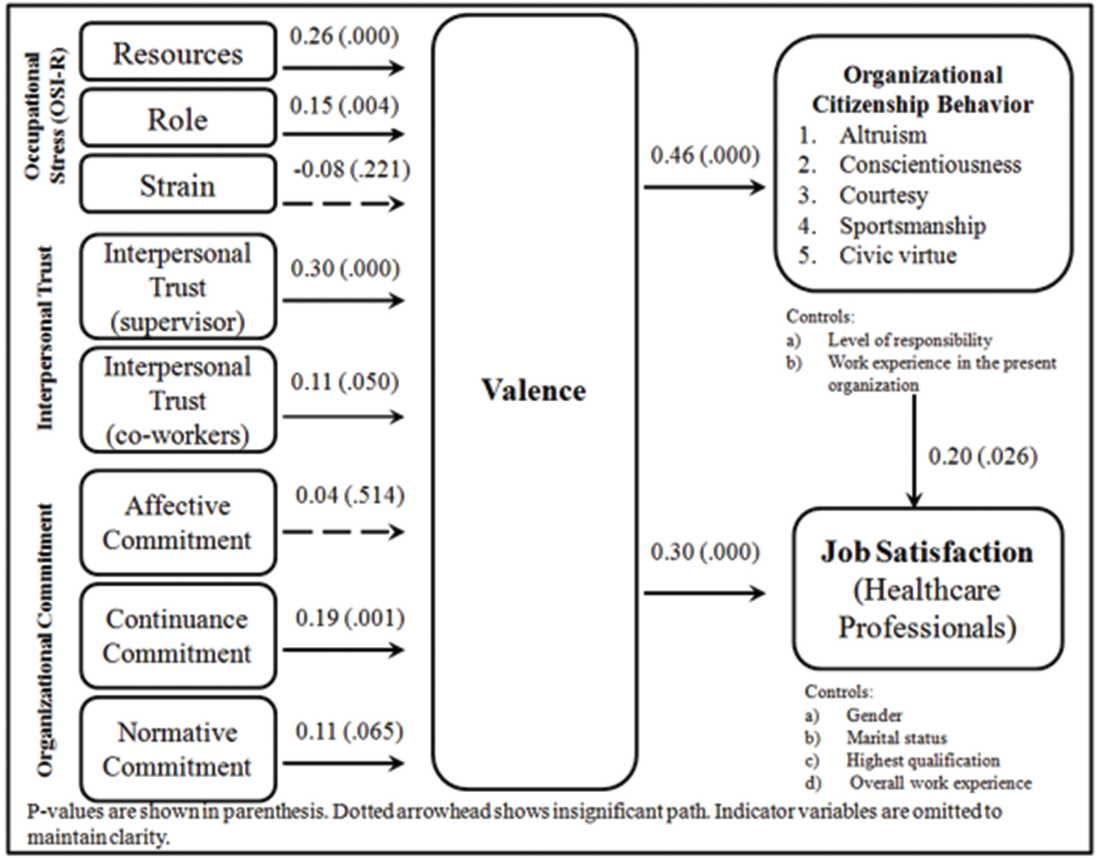

\section{Predictive Relevance Using Cross-validated Redundancy Analysis}

Lastly, according to the guidelines of Hair et al. (2012), the predictive relevance of both latent variables $\left(Q^{2}\right)$ and each of their indicators $\left(q^{2}\right)$ serve as the last requirement to test the structural (or inner) model as shown in Table 5. A blindfolding procedure was followed to estimate predictive relevance $\left(Q^{2}\right)$ and $q^{2}$. The $Q^{2}$ value of three LVs (i.e. job satisfaction $\mathrm{OCB}$, and valence) and $\left(q^{2}\right)$ each of the indicator variables are above zero which reflects that the structural model has good predictive relevance and the measured variables are well reconstructed (Henseler et al., 2009).

\section{Discussion and Managerial Implications}

Both resources and role have shown significant impact on valence (of job satisfaction). Likewise, other professions, the healthcare sector of Pakistan requires highly professional and self-motivated employees who could not only meet their individual role requirements but also perform better in a team formation. The sample included responses from 263 managerial employees ( 90.1 percent) and 108 respondents ( 37 percent) have both teaching and administrative responsibilities. 


\begin{tabular}{lcc} 
Table 5 & & \\
Predictive Relevance Using Crossvalidated & Redundancy & Analysis \\
\hline Q-square & Indicator & q-square \\
\hline \multirow{3}{*}{ Job Satisfaction $=0.07$} & JS_1 & 0.14 \\
& JS_2 & 0.03 \\
& JS_3 & 0.02 \\
\hline & OCB_1 & 0.12 \\
Organizational Citizenship Behavior $=0.09$ & OCB_11 & 0.04 \\
& OCB_3 & 0.11 \\
& OCB_8 & 0.10 \\
& OCB_9 & 0.08 \\
\hline & Valence_10 & 0.22 \\
& Valence_11 & 0.24 \\
& Valence12 & 0.25 \\
& Valence_13 & 0.23 \\
& Valence_4 & 0.08 \\
Valence $=0.22$ & Valence_5 & 0.18 \\
& Valence_7 & 0.24 \\
& Valence_8 & 0.22 \\
& Valence_9 & 0.29 \\
\hline
\end{tabular}

This work pressure tends to increase occupational role stress rendering them very cautious and attentive towards their daily routines. Their occupational role requires them to make operational, tactical, and strategic decisions which do not allow them to make unavoidable mistakes in their medical profession. More specifically, the sample consists of 186 females (64 percent approx.) and 37 percent parents. Irawanto, Noermiyati, and Primasari (2015) have argued that occupational stress mainly affects the performance of female employees. However, the demographic variables significantly affect a number of stress variables (Spielberger \& Reheiser, 1994). Generally speaking, it is conjectured that female and male healthcare professionals take their home life and occupation as their primary obligation respectively (Rashid \& Talib, 2015). Hence, it is suggested that the top management of a health care institution in Karachi should take these matters into account, particularly at the time of recruitment and selection (Adil, 2015) of a healthcare professional.

Besides, it is very important to formulate different corporate-wide plans, e.g. 'workplace health promotion programs' (Nowrouzi et al., 2015) and exercises to help the healthcare professional mitigate their stress related issues. Failure to do so often results in aggressions, psychological and physical impairments and ultimately either straightaway turnover or even death at workplace (Leigh, 1995; Mosadeghrad, Ferlie, \& Rosenberg, 2011) because of work overload (called 'Karoshi' in Japan). In addition, considering the Likert-scale items of occupational resource in the context of the both private and public healthcare institution of Karachi, if the person knows the standard operating procedures, the contact person(s) when occupational needs arise, is empowered to adjust work duties according to his/her priorities and takes balance diet then of course, the valence (of job satisfaction) gets increased.

Commitment is the process of identification with the aims of an organization's several areas (Reichers, 1985). It can take various forms and, arguably, have the potential to influence organizational effectiveness and employee well-being (Ahmed \& Islam, 2011; Islam et al., 2012). In today's hyper-competitive world, organizations face severe difficulty in 
observing high performance from their employees in case of low commitment. In the past, organizations secured the loyalty of their employees by guaranteeing them job security. But due to high competitive pressure, organizations have to move towards downsizing, restructuring and strategic transformations which create an unsecure organizational climate.

To meet the potential-increasing requirements of this competitive environment, one of the key components for survival is the ability of the organization to use human resource effectively and efficiently (Ahmed \& Islam, 2011). The appointment of 'right' worker is crucial, but it is more important for the organization's ability to establish a portfolio of committed workforce (Rehan \& Islam, 2013). According to Islam et al. (2012), organizational commitment reflects a psychological state of an employee because the person tends to demonstrate a higher level of ownership, which could ultimately result in better performance (Adil, 2015). These highly self-motivated employees start to participate in various organizational activities with a holistic belief in knowledge sharing with all concerned. Consequently, better performance could be observed in the presence of several other antecedences e.g. organizational justice, working conditions, career growth opportunities, commitment to change (Adil, 2016), low rate of workplace incivility (Cortina, Magley, Williams, \& Langhout, 2001), recognition, leader's change-promoting behavior (Adil, 2014), etc.

The results also show that interpersonal trust between supervisors and co-workers have significant impact on valence of job satisfaction. Trust is considered as one of the major antecedents of developing effective and enriching organizational climate. $\mathrm{Ng}$ (2015) argued that a trustworthy employer can inherently inculcate an organizational commitment among employees. Moreover, cost-effective working conditions may further reinforce a better working environment in order to achieve optimum performance of healthcare professionals. Therefore, the study recommends that the management of healthcare institutions should invest in promoting a trusting culture in their organizations (Barthelemy, 2001; Oh, Gallivan, \& Kim, 2006). It is imperative to recognize that this is the trust which could assist healthcare professionals embark on better organizational commitment and OCB. People start to take more ownership in the job and working units and collectively over a period of time, a high-performance work system (HPWS) could be established. Knowing that this is a challenging task where there is a high rate of occupational stress, both supervisors and healthcare staff may work together in order to mitigate the repercussion of stress and, no doubt, this could only be achieved once there is an interpersonal trust between co-workers and officers of the healthcare institution.

The statistical result uncovers that valence (of job satisfaction) significantly influence OCB and job satisfaction of the healthcare professionals in Karachi. This finding has been found consistent with the findings of Cabrera and Cabrera (2005) that the valence of job satisfaction enhances employee's citizenship behaviors. Therefore, it is essential for firms to select the right person-organization fit for employees with necessary personality traits, value, intention and inclination to share knowledge (Chatman, 1991) so that firms will be able to create a better organizational environment and culture for knowledge sharing. This selective hiring practice reaffirmed the finding of Goodman and Leyden (1991) that the new employees are able to adapt to the new working environment, thus enhancing the 
interchange of knowledge among old and new employees. Hence, it is also recommended that it is beneficial to include OCB as one of the major key indicators of employee's performance.

Besides, this study has numerous implications to healthcare management and staff. The OCB has shown a significant impact on job satisfaction. Not to mention, this is the devising platform which enables employees to perform at their best. Although OCB represents a discretionary behavior, it tends to reflect a high level of self-motivation and a strong belief in the management that their efforts would be recognized and hence rewarded within financial constraints of the organization. In line with both monetary and non-monetary rewards, employees seek for better professional growth, mental piece with SMART targets, work-life balance and manageable occupational stress. For this, employees need to behave as per the rules and regulations. Moreover, the psychological contract between the manager and the sub-ordinates should be clarified as early as possible. Later on, employees will be engaged in their routine activities and on-the job trainings may deter the smooth functioning and delivery of the healthcare services. It is equally important to invest in the healthcare services (Smith, Mitra, \& Narasimhan, 1998) because value-added services to patients may also enhance their level of satisfaction which could in turn, motivate the healthcare employees.

It is also predicted that the supply and demand of professionals for healthcare will extend until 2012 (Geer, 2006). Therefore, this intricate situation will further put more work load on existing employees causing them leaving their job. They could do this because of getting job satisfaction so the healthcare management must continuously and vigorously look after the workload of health professionals as they are more vulnerable to stress and fatigue at work (Moore \& Love, 2005), which can direct them to leave as they have high levels of intention (Moore \& Burke, 2002). It may be completed through, such as, the reduction of role conflict and more benefits from interferences and stress management.

\section{Directions for Future Research}

Future studies should study the multivariate and causal relationship between the quality of work life (QWL) and occupational stress among healthcare professionals of Pakistan. Different constructs may be taken as a mediator or moderator as per the research needs. These variables include leader-member exchange relationship, workplace incivility, self-efficacy, and psychological empowerment. This suggested domain has also been an under-researched area in the healthcare sector of other major cities of Pakistan. More specifically, a multi-trait multi-method (MTMM) design may also be used to measure multiple traits by multiple methods (Byrne, 2013). In addition, future studies may also analyze the non-linear moderating effect of organizational tenure on the relationship between affective organizational commitment and OCB ( $\mathrm{Ng} \&$ Feldman, 2011). 


\section{Conclusion}

This study analyzed the impact of three cognitive forces (i.e. occupational stress, interpersonal trusts, and organizational commitment) on valence, OCB and job satisfaction in the healthcare institutions of Karachi. Using PLS-SEM algorithm, hypotheses are tested with a non-parametric bootstrapping method and the predictive relevance using crossvalidated redundancy analysis of both latent variables and indicators are measured by blindfolding procedure. The results show that the all cognitive forces have significant impact on valence with the minor exception of affective commitment and strain. Secondly, valence is significantly associated with both OCB and job satisfaction. Lastly, OCB is also found significant to predict job satisfaction in the healthcare sector of Karachi. The findings of this study substantially contribute in the under-researched domain of valence, OCB and job satisfaction in the healthcare sector of Pakistan. 


\section{References}

Abdel-Halim, A. A. (1982). Social support and managerial affective responses to job stress. Journal of Organizational Behavior, 3(4), 281-295.

Adil, M. S. (2014). Impact of leader's change-promoting behavior on readiness for change: A mediating role of organizational culture. Journal of Management Sciences, 1(2), 102 123.

Adil, M. S. (2015). Strategic human resource management practices and competitive priorities of the manufacturing performance in Karachi. Global Journal of Flexible Systems Management, 16(1), 37-61.

Adil, M. S. (2016). Impact of change readiness on commitment to technological change, focal, and discretionary behaviors: Evidence from the manufacturing sector of Karachi. Journal of Organizational Change Management, 29(2), 222-241.

Adil, M. S., Awais, A., Khan, I., \& Qureshi, M. A. (2019). Leader-member exchange, job satisfaction, affective commitment, and job stress: Implications for turnover intentions using covariance-based structural equation modelling. Pakistan Business Review, 21(2).

Ahmed, I., \& Islam, T. (2011). Decoding the relationship between employee's jobs related behaviors: A study of telecom sector of Pakistan. International Journal of Business and Social Science, 2(8), 245-252.

Allen, N. J., \& Meyer, J. P. (1990). The measurement and antecedents of affective, continuance and normative commitment to the organization. Journal of Occupational and Organizational Psychology, 63(1), 1-18.

American Association of Colleges of Nursing. (2002). Hallmarks of the professional nursing practice environment. Journal of Professional Nursing, 18(5), 295-304.

Andersson, L. M., \& Bateman, T. S. (1997). Cynicism in the workplace: Some causes and effects. Journal of Organizational Behavior: The International Journal of Industrial, Occupational and Organizational Psychology and Behavior, 18(5), 449-469.

Aulakh, P. S., \& Gencturk, E. F. (2000). International principal-agent relationships: Control, governance and performance. Industrial Marketing Management, 29(6), 521-538.

Barthelemy, J. (2001). The hidden costs of IT outsourcing. MIT Sloan Management Review, 42(3), 60-69.

Bateman, T. S., \& Organ, D. W. (1983). Job satisfaction and the good soldier: The relationship between affect and employee "citizenship". Academy of Management Journal, 26(4), 587-595.

Beehr, T. A., King, L. A., \& King, D. W. (1990). Social support and occupational stress: Talking to supervisors. Journal of Vocational Behavior, 36(1), 61-81.

Ben-Zur, H., Yagil, D., \& Oz, D. (2005). Coping strategies and leadership in the adaptation to social change: The Israeli kibbutz. Anxiety, Stress E Coping, 18(2), 87-103.

Bryman, A. (2012). Social research methods. Oxford University Press.

Byrne, B. M. (2013). Structural equation modeling with eqs: Basic concepts, applications, and programming. New York: NY, Taylor and Francis Group.

Cabrera, E. F., \& Cabrera, A. (2005). Fostering knowledge sharing through people management practices. The International Journal of Human Resource Management, 16(5), 
720-735.

Carver, C. S., Scheier, M. F., \& Weintraub, J. K. (1989). Assessing coping strategies: A theoretically based approach. Journal of Personality and Social Psychology, 56(2), 267283.

Cenfetelli, R. T., \& Bassellier, G. (2009). Interpretation of formative measurement in information systems research. MIS Quarterly, 689-707.

Chatman, J. A. (1991). Matching people and organizations: Selection and socialization in public accounting firms. Administrative Science Quarterly, 36(3), 459-484.

Chen, S.-H., Yang, C.-C., Shiau, J.-Y., \& Wang, H.-H. (2006). The development of an employee satisfaction model for higher education. The TQM Magazine, 18(5), 484500.

Chiaburu, D. S., Oh, I.-S., Berry, C. M., Li, N., \& Gardner, R. G. (2011). The fivefactor model of personality traits and organizational citizenship behaviors: A metaanalysis. Journal of Applied Psychology, 96(6), 1140-1166.

Cook, J., \& Wall, T. (1980). New work attitude measures of trust, organizational commitment and personal need non-fulfilment. Journal of Occupational and Organizational Psychology, 53(1), 39-52.

Cooper, C. L., \& Marshall, J. (2013). Occupational sources of stress: A review of the literature relating to coronary heart disease and mental ill health. Journal of Occupational Psychology, 49, 3-23.

Cortina, L. M., Magley, V. J., Williams, J. H., \& Langhout, R. D. (2001). Incivility in the workplace: Incidence and impact. Journal of Occupational Health Psychology, 6(1), 64-80.

Cyr, D. (1999). High tech, high impact: Creating Canada's competitive advantage through technology alliances. The Academy of Management Executive, 13(2), 17-26.

Davison, A. C., \& Hinkley, D. V. (1997). Bootstrap methods and their application. Cambridge: Cambridge University Press.

Diamantopoulos, A., \& Winklhofer, H. M. (2001). Index construction with formative indicators: An alternative to scale development. Journal of Marketing Research, 38(2), 269-277.

Djukic, M., Kovner, C. T., Brewer, C. S., Fatehi, F. K., \& Cline, D. D. (2013). Work environment factors other than staffing associated with nurses' ratings of patient care quality. Health Care Management Review, 38(2), 105-114.

Edwards, J. R. (2011). The fallacy of formative measurement. Organizational Research Methods, 14(2), 370-388.

Efron, B., \& Tibshirani, R. J. (1994). An introduction to the bootstrap. New York: Chapman Hall.

Eisenberg, R., Fasolo, P., \& Davis-LaMastro, V. (1990). Perceived organizational support and employee diligence, commitment, and innovation. Journal of Applied Psychology, 75(1), 51-59.

Faul, F., Erdfelder, E., Buchner, A., \& Lang, A.-G. (2009). Statistical power analyses using $\mathrm{G}^{*}$ Power 3.1: Tests for correlation and regression analyses. Behavior Research Methods, 41(4), 1149-1160.

Fitzgerald, S. T., Brown, K. M., Sonnega, J. R., \& Ewart, C. K. (2005). Early antecedents of 
adult work stress: Social-emotional competence and anger in adolescence. Journal of Behavioral Medicine, 28(3), 223-230.

Geer, D. (2006). Software developer profession expanding. IEEE Software, 23(2), 112-115.

Goodman, P. S., \& Leyden, D. P. (1991). Familiarity and group productivity. Journal of Applied Psychology, 76(4), 578-586.

Hair, J. F., Ringle, C. M., \& Sarstedt, M. (2011). PLS-SEM: Indeed a silver bullet. Journal of Marketing Theory and Practice, 19(2), 139-152.

Hair, J. F., Sarstedt, M., Ringle, C. M., \& Mena, J. A. (2012). An assessment of the use of partial least squares structural equation modeling in marketing research. Journal of the Academy of Marketing Science, 40(3), 414-433.

Hair Jr, J. F., Hult, G. T. M., Ringle, C., \& Sarstedt, M. (2016). A primer on partial least squares structural equation modeling (PLS-SEM). USA: Sage Publications, Inc.

Henseler, J., Ringle, C. M., \& Sinkovics, R. R. (2009). The use of partial least squares path modeling in international marketing. Advances in International Marketing, 20(1), 277-319.

Irawanto, D. W., Noermiyati, \& Primasari, D. (2015). The effect of occupational stress on work performance of female employees: Study in Indonesia. Asia-Pacific Journal of Management Research and Innovation, 11(4), 336-345.

Islam, T., Ahmad, Z., Ahmed, I., Ahmad, A., Muhammad, S., \& Muhammad, S. K. (2012). Does compensation and demographical variable influence on teachers commitment and job satisfaction? A study of University of the Punjab, Pakistan. International Journal of Business and Management, 7(4), 35-43.

Jehn, K. A., \& Shah, P. P. (1997). Interpersonal relationships and task performance: An examination of mediation processes in friendship and acquaintance groups. Journal of Personality and Social Psychology, 72(4), 775-790.

Kramer, M., \& Hafner, L. P. (1989). Shared values: Impact on staff nurse job satisfaction and perceived productivity. Nursing Research, 38(3), 172-177.

Kramer, R. M., \& Tyler, T. R. (1996). Trust in organizations: Frontiers of theory and research. Thousand Oaks, CA: Sage Publications.

Kristensen, T. S. (1996). Job stress and cardiovascular disease: A theoretic critical review. Journal of Occupational Health Psychology, 1(3), 246-260.

Lake, E. T. (2002). Development of the practice environment scale of the nursing work index. Research in Nursing \& Health, 25(3), 176-188.

Lake, E. T. (2007). The nursing practice environment. Medical Care Research and Review, 64(2), 104-122.

Lambert, E. G., Hogan, N. L., \& Griffin, M. L. (2007). The impact of distributive and procedural justice on correctional staff job stress, job satisfaction, and organizational commitment. Journal of Criminal Justice, 35(6), 644-656.

Lapierre, L. M., \& Hackett, R. D. (2007). Trait conscientiousness, leader-member exchange, job satisfaction and organizational citizenship behaviour: A test of an integrative model. Journal of Occupational and Organizational Psychology, 80(3), 539-554.

Lee, T. W., Mitchell, T. R., Holtom, B. C., McDaneil, L. S., \& Hill, J. W. (1999). The unfolding model of voluntary turnover: A replication and extension. Academy of Management Journal, 42(4), 450-462. 
Leigh, J. P. (1995). Causes of death in the workplace. Westport: CT, Greenwood Publishing Group.

LePine, J. A., Erez, A., \& Johnson, D. E. (2002). The nature and dimensionality of organizational citizenship behavior: A critical review and meta-analysis. American Psychological Association.

McAllister, D. J. (1995). Affect-and cognition-based trust as foundations for interpersonal cooperation in organizations. Academy of Management Journal, 38(1), $24-59$.

Meyer, J. P., \& Allen, N. J. (1991). A three-component conceptualization of organizational commitment. Human Resource Management Review, 1(1), 61-89.

Meyer, J. P., Allen, N. J., \& Gellatly, I. R. (1990). Affective and continuance commitment to the organization: Evaluation of measures and analysis of concurrent and timelagged relations. Journal of Applied Psychology, 75(6), 710-720.

Meyer, J. P., \& Herscovitch, L. (2001). Commitment in the workplace: Toward a general model. Human Resource Management Review, 11(3), 299-326.

Mitchell, T. R. (1974). Expectancy models of job satisfaction, occupational preference and effort: A theoretical, methodological, and empirical appraisal. Psychological Bulletin, 81(12), 1053-1077.

Moore, J. E., \& Burke, L. A. (2002). How to turn around 'turnover culture' in it. Communications of the ACM, 45(2), 73-78.

Moore, J. E., \& Love, M. S. (2005). IT professionals as organizational citizens. Communications of the ACM, 48(6), 88-93.

Moorman, R. H. (1993). The influence of cognitive and affective based job satisfaction measures on the relationship between satisfaction and organizational citizenship behavior. Human Relations, 46(6), 759-776.

Morrison, E. W. (1996). Organizational citizenship behavior as a critical link between HRM practices and service quality. Human Resource Management, 35(4), 493-512.

Mosadeghrad, A. M., Ferlie, E., \& Rosenberg, D. (2011). A study of relationship between job stress, quality of working life and turnover intention among hospital employees. Health Services Management Research, 24(4), 170-181.

Mowday, R. T., Steers, R. M., \& Porter, L. W. (1979). The measurement of organizational commitment. Journal of Vocational Behavior, 14(2), 224-247.

$\mathrm{Ng}, \mathrm{T}$. W. (2015). The incremental validity of organizational commitment, organizational trust, and organizational identification. Journal of Vocational Behavior, 88, 154-163.

$\mathrm{Ng}$, T. W., \& Feldman, D. C. (2011). Affective organizational commitment and citizenship behavior: Linear and non-linear moderating effects of organizational tenure. Journal of Vocational Behavior, 79(2), 528-537.

Ng, T. W., Lam, S. S., \& Feldman, D. C. (2016). Organizational citizenship behavior and counterproductive work behavior: Do males and females differ? Journal of Vocational Behavior, 93, 11-32.

Nizam, S. A., \& Adil, M. S. (2014). Determiants of teacher's job satisfaction: Evidence from the primary and secondary schools of Karachi. Journal of Education and Social Sciences, 2(2), 109-126.

Nowrouzi, B., Lightfoot, N., Larivière, M., Carter, L., Rukholm, E., Schinke, R., \& Belanger-Gardner, D. (2015). Occupational stress management and burnout in- 
terventions in nursing and their implications for healthy work environments: A literature review. Workplace Health E Safety, 63(7), 308-315.

Oh, W., Gallivan, M. J., \& Kim, J. W. (2006). The market's perception of the transactional risks of information technology outsourcing announcements. Journal of Management Information Systems, 22(4), 271-303.

Orchard, C. A., Curran, V., \& Kabene, S. (2005). Creating a culture for interdisciplinary collaborative professional practice. Medical Education Online, 13(10), 1-3.

Organ, D. W., Podsakoff, P. M., \& MacKenzie, S. B. (2005). Organizational citizenship behavior: Its nature, antecedents, and consequences. CA: Sage, Thousand Oaks.

Oshagbemi, T. (2003). Personal correlates of job satisfaction: Empirical evidence from UK universities. International Journal of Social Economics, 30(12), 1210-1232.

Podsakoff, N. P., Whiting, S. W., Podsakoff, P. M., \& Blume, B. D. (2009). Individualand organizational-level consequences of organizational citizenship behaviors: A meta-analysis. Journal of Applied Psychology, 94(1), 122-141.

Podsakoff, P. M., MacKenzie, S. B., Lee, J.-Y., \& Podsakoff, N. P. (2003). Common method biases in behavioral research: A critical review of the literature and recommended remedies. Journal of Applied Psychology, 88(5), 879-903.

Podsakoff, P. M., \& Organ, D. W. (1986). Self-reports in organizational research: Problems and prospects. Journal of Management, 12(4), 531-544.

Rashid, I., \& Talib, P. (2015). Occupational stress and coping styles among doctors: Role of demographic and environment variables. Vision, 19(3), 263-275.

Rehan, M. F., \& Islam, T. (2013). Relationship between organizational commitment and citizenship behaviours. World Journal of Management and Behavioral Studies, 1(1), 2432.

Reichers, A. E. (1985). A review and reconceptualization of organizational commitment. Academy of Management Review, 10(3), 465-476.

Ringle, C. M., Wende, S., \& Becker, J.-M. (2015). Smartpls 3. SmartPLS GmbH, Boenningstedt.

Robinson, S. L. (1996). Trust and breach of the psychological contract. Administrative Science Quarterly, 41, 574-599.

Romzek, B. S. (1990). Employee investment and commitment: The ties that bind. Public Administration Review, 50(3), 374-382.

Roth, S., \& Cohen, L. J. (1986). Approach, avoidance, and coping with stress. American Psychologist, 41(7), 813-819.

Sarkkinen, M., \& K'assi, T. (2015). Predictive modeling of innovation capability in a regional context. International Journal of Innovation and Technology Management, 12(1), $1-25$.

Schaufeli, W., Leiter, M., \& Kalimo, R. (1995). The general burnout inventory: A selfreport questionnaire to assess burnout at the workplace. Work, Stress and Health, 95, $14-16$.

Schriesheim, C. A. (1979). The similarity of individual directed and group directed leader behavior descriptions. Academy of Management Journal, 22(2), 345-355.

Scott, S. G., \& Bruce, R. A. (1994). Determinants of innovative behavior: A path model of individual innovation in the workplace. Academy of Management Journal, 37(3), 
580-607.

Sekaran, U., \& Bougie, R. (2016). Research methods for business: A skill building approach. UK, West Sussex: John Wiley \& Sons Ltd.

Shaffer, J. P. (1995). Multiple hypothesis testing. Annual Review of Psychology, 46(1), 561584.

Smith, M. A., Mitra, S., \& Narasimhan, S. (1998). Information systems outsourcing: A study of pre-event firm characteristics. Journal of Management Information Systems, 15(2), 61-93.

Spielberger, C. D., \& Reheiser, E. C. (1994). The job stress survey: Measuring gender differences in occupational stress. Journal of Social Behavior and Personality, 9(2), 199218.

Tabachnick, B., \& Fidell, L. (2013). Using multivariate statistics. Boston, MA: Pearson Education.

Teas, R. K. (1981). A within-subject analysis of valence models of job preference and anticipated satisfaction. Journal of Occupational and Organizational Psychology, 54(2), 109-124.

Vroom, V. H. (1964). Work and motivation. New York, NY: Wiley.

Williams, L. J., \& Anderson, S. E. (1991). Job satisfaction and organizational commitment as predictors of organizational citizenship and in-role behaviors. Journal of Management, 17(3), 601-617.

World Health Organization. (2014). A universal truth: No health without a workforce. Geneva, Switzerland. Retrieved from http://www.who.int/workforcealliance/ knowledge/resources/hrhreport2013/en/ 